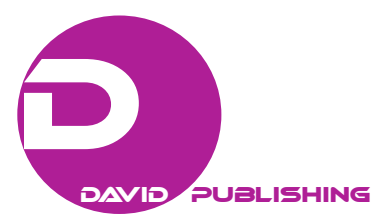

\title{
Human Potential Development: A New HRD Model for Turbulent Times
}

\author{
Asoka Nimal Jinadasa \\ Institute of Personnel Management, Colombo, Sri Lanka
}

\begin{abstract}
Conventional human resource development (HRD) programs focus mainly on improving employees' hard skills comprising of job-specific knowledge, skills, tools, and processes, while minimal emphasis is placed on developing their intuitive, attitudinal, behavioral, and interpersonal soft skills, which are essential for sustaining organizational success in today's unpredictable world. This conceptual paper presents a new model for HRD based on human potential development (HPD) for unleashing the vast inborn mental and physical power lying mostly dormant within every employee at every level. HPD aims to create an employee-driven, organization-wide, and everyday business innovation ideology that can sustain success even under difficult operating conditions. HPD programs draw on diverse sources such as behavioral psychology, neuroscience, oriental martial arts, and Himalayan energy techniques for energizing and empowering employees at all levels. A foundation underlying HPD programs is provided by the wisdom-skills matrix, where developing wisdom (knowing what to do next) and skills (knowing how to do it) are considered the two key ingredients of individual and organizational success in an increasingly turbulent world. A mechanism for conceptualizing and developing wisdom and skills is provided by the five dimensional model of success and leadership, which is summarized and symbolized by heart (emotional intelligence), mind (analytical and intuitive intelligence), passion (energy that fuels high levels of performance), focus (reaching goals despite setbacks), and health (immunity from stress and illness).
\end{abstract}

Keywords: human resource development (HRD), wisdom-skills matrix, five dimensions of success and leadership, soft skills, organizational performance, employee engagement

\section{Introduction}

Despite abundant literature theorizing on "what" human resource management should do to sustain organizational success under increasingly turbulent conditions, there is scant reference to "how" human resource development (HRD) programs could achieve it (Wentz, 2012). Conventional HRD programs focus mainly on improving employees' hard skills comprising of job-specific knowledge, skills, tools, and processes, while minimal emphasis is placed on developing their intuitive, attitudinal, behavioral, and interpersonal soft skills, which are essential for overcoming complex challenges and sustaining organizational success under today's unpredictable operating conditions.

This conceptual paper introduces human potential development (HPD) as a new and holistic model for

Asoka Nimal Jinadasa, Ph.D., honorary member and strategic planner of the Institute of Personnel Management (IPM), Colombo, Sri Lanka.

Correspondence concerning this article should be addressed to Dr. Asoka Jinadasa, 139 T20 Watta, Baseline Road, Colombo 8, Sri Lanka. E-mail: asokajin@gmail.com. 
HRD for energizing, empowering, and engaging employees for sustaining organizational success under all conditions. This new HPD-based HRD model provides the foundation for maximizing organizational performance through empowered employees at all levels who can quickly sense and respond to risks and opportunities in the operating environment, while continuing to perform their daily tasks. In engineering terms, this is analogous to developing an adaptive control system that can sustain any desired level of performance by continuously detecting and adapting to changes in the operating conditions. The conventional HRD model is not geared to meeting a similar requirement that organizations have for sustaining performance under turbulent conditions, as suggested by many studies and reports.

\section{Literature Review}

According to a worldwide survey across major industry sectors in the Asia-Pacific, Europe, North and Latin America, the HR function was often dismissed as non-essential or ineffective. Only 17\% out of 418 senior executives interviewed maintained that HR is demonstrating its value to the business (KPMG, 2012). This survey also suggested that HRD has to start delivering sustained and differentiated performance improvement to business, which it has not been doing for the past 15 years. It highlighted the need for HRD to recast its strategy to align itself with the changing needs of the entire organization, instead of focusing mainly on managing HR-related tasks and developing work-related Hard Skills.

It's said that the competencies that served HR well in the past will not be enough to propel it into the future (McIlvaine, 2012). This comment highlighted the difficulty HRD faces in "future-proofing" the success of an enterprise through employee competency development, given the impossibility of predicting the outcomes of growing turbulence in operating environments. Two recent HR competency models offer insights into this predicament.

A globally-researched report on competencies for HR professionals identified six core areas that included non-tangibles such as: understanding external trends (social, technological, economic, political, environmental, and demographic); translating them into internal decisions and actions; building personal trust through business acumen and clear communication; and innovating and integrating HR practices into solutions to solve future business problems (D. Ulrich, Younger, Brockbank, \& M. Ulrich, 2011). Another globally researched competency model for HR identified nine competencies out of which eight were behavioral, as summarized by "knowledge (i.e. mainly hard skills) + behavior (i.e. mainly soft skills) = success" (Society for Human Resource Management, 2012).

Both these competency models highlighted the need to develop behavioral soft skills of employees. Conventional HRD programs typically develop employees' work-related hard skills, probably because they are an extension of the education and certification system, and form the basis of most employee evaluation schemes. There is little focus on developing employees' soft skills comprising of intuitive, emotional, attitudinal, behavioral, and interpersonal competencies, which hold the key to sustaining organizational success and increasing employee engagement.

\section{Employee Engagement}

As Klaus (2007) argued, it is rarely a shortfall in technical expertise (hard skills) that limits people's careers, motivation, and engagement, but rather, shortcomings in their social communication and self-management behaviors (soft skills). The changing role of employees in a turbulent corporate world was summarized by 
McCann (n.d.), when he said that people no longer live in a world where one may look solely to the boss for answers or motivation; each individual must take responsibility for pursuing knowledge, insight, and possibility, and muster motivation and courage to take calculated risks in devising and implementing strategy.

More than 100 studies have shown that human talent expressed through employee engagement is one of the key drivers of sustained organizational performance and competitiveness (Schwartz, 2012). One of the boosters of employee engagement is skill development, which enhances revenue growth, profitability, innovation, productivity, and customer loyalty, and reduces cycle time (Kaye \& Giulioni, 2012). HPD-based HRD programs can maintain high levels of employee engagement by unleashing their mental, emotional, attitudinal, behavioral, and interpersonal competencies for achieving both career and organizational success.

\section{Sustainable Employee Engagement}

A global workforce study by Towers Watson (2012) covered over 32,000 full-time employees working in large and midsized organizations across a range of industries in 29 markets around the world. It provided the most powerful case yet for the connection between significantly higher organizational operating margins and "sustainable engagement" - a new and more robust definition of engagement based on workplace energy.

In its analysis of 50 global companies, those with low traditional employee engagement scores had an average one-year operating margin just under $10 \%$; those with high traditional employee engagement had a slightly higher margin of 14\%; but, those with the highest sustainable engagement scores had an average one-year operating margin almost three times higher at $27 \%$, as shown in Table 1.

Table 1

\section{Link Between Employee Engagement and Average Annual Operating Margins}

\begin{tabular}{ll}
\hline Companies with: & Average annual operating margin: \\
\hline Low traditional engagement scores & just under 10\% \\
High traditional engagement scores & $14 \%$ \\
Highest sustainable engagement scores & $27 \%$ \\
\hline
\end{tabular}

Source: Towers Watson (2012).

Employee engagement, traditionally defined as the willingness to invest discretionary effort on the job, is not enough to give employers the sustained performance lift they need in today's fiercely competitive operating environment. This study suggested that businesses appeared to be at a critical tipping point in their ability to maintain employee engagement over time. While most were already running their businesses very differently in today's marketplace, a surprisingly large number did not appear to be keeping pace in terms of how they were supporting and developing the people assigned to execute the work - they appeared to be running 21st-century businesses with 20th-century workplace practices and programs (Towers Watson, 2012).

Regarding the gaps in the traditional engagement model identified in the above study, closing the first gap requires effectively enabling workers with internal support, resources, and tools. This can range from helpful supervisors to online tools and processes that provide information and guidance to make good job-related decisions in real-time. Closing the second gap requires creating an energizing work environment by promoting employees' physical, emotional, and social well-being, embedded in a culture that focuses on workers' health, safety, and security, both physical and emotional. Schwartz (2012) suggested adding mental and spiritual wellbeing to the above list for liberating extra energy derived from the capacity for absorbed focus and a strong sense of purpose. 
The Towers Watson's study (2012) brings into sharp relief the importance of energizing and empowering employees for achieving and sustaining extraordinary organizational performance. Employers have to think fresh beyond the current HRD programs, and embrace the notion of enhancing employee and workplace energy through HPD-based HRD, which must place greater emphasis on developing soft skills.

\section{Growing Importance of Soft Skills}

People are leaving the old way of thinking with its over-dependence on the logical mind; a new kind of thought is awakening, characterized by a balance between logical thinking and intuition (Österberg, 2003). Increasingly volatile conditions require HRD to be founded on a new paradigm based on the intellectual capital possessed by the workforce (Maynard \& Mehrtens, 1996). These observations are supported by the fact that, over and above academic qualifications or business acumen, $81 \%$ of business leaders have cited confidence, enthusiasm, and entrepreneurial spirit as the most important characteristics (soft skills) they seek when recruiting (Milne, 2012).

A study by Oxford Economics (2012) identified competencies expected to be in high demand over five to 10 years. These included: digital business skills (such as understanding software and systems), agile thinking skills (such as innovation; dealing with complexity and ambiguity; and the ability to see the big picture), interpersonal and communication skills (for co-creativity and relationship building), and global operating skills (such as the ability to manage employees with cultural diversity). This study highlighted the need for the parallel development of work-related Hard Skills, and attitudinal, behavioral, and interpersonal soft skills.

According to the International Monetary Fund (2014), risks had not disappeared though acute risks had decreased; potential growth in many advanced economies was very low and appeared to have decreased in many emerging market economies; the financial system remained at risk due to incomplete financial reform; and current dynamics suggested a changing environment for emerging markets and developing economies. In such countries, developing soft skills would increase workforce confidence, deepen their awareness, develop their intuition, strengthen their motivation and leadership, and integrate new thinking into their daily work-all of which will help them navigate their economies and organizations through turbulent times by integrating their analytical and intuitive skills for managing risks and exploiting opportunities.

\section{Whole Brain Integration}

Neuroscientists have found clinical evidence for the existence of two distinct kinds of consciousness functioning separately but simultaneously within the human brain (Erdmann \& Stover, 1991). The left half of the brain plays a dominant role in analytical and verbal processes, while creative processes mainly take place in the right half, as depicted in Figure 1.

The left-brain is generally associated with the conscious mind and the right-brain with the subconscious mind. The conscious mind is very good at linear thinking, mathematics, planning, logic, and etc., while the subconscious mind is the source of nonlinear thinking, inspiration, intuition, and etc.. Whole brain integration, which means using the left and right sides of the brain together, improves the effectiveness of the human brain by as much as five to 10 times (Erdmann \& Stover, 1991).

Even so, left-brain consciousness is clearly favored by the educational and employment systems; it is primarily objective and dominates the daily activities of most people and organizations. Right-brain consciousness receives secondary consideration in the mainstream educational system; it is primarily subjective and finds its greatest expression in the arts. Nevertheless, whole brain integration has become increasingly 
important in today's fiercely competitive business world where employees' creativity and innovation hold the key to organizational success (Gupta, 2011). This requires employees to be trained in functioning at mental states that are more conducive to unleashing their vast inborn human potential.

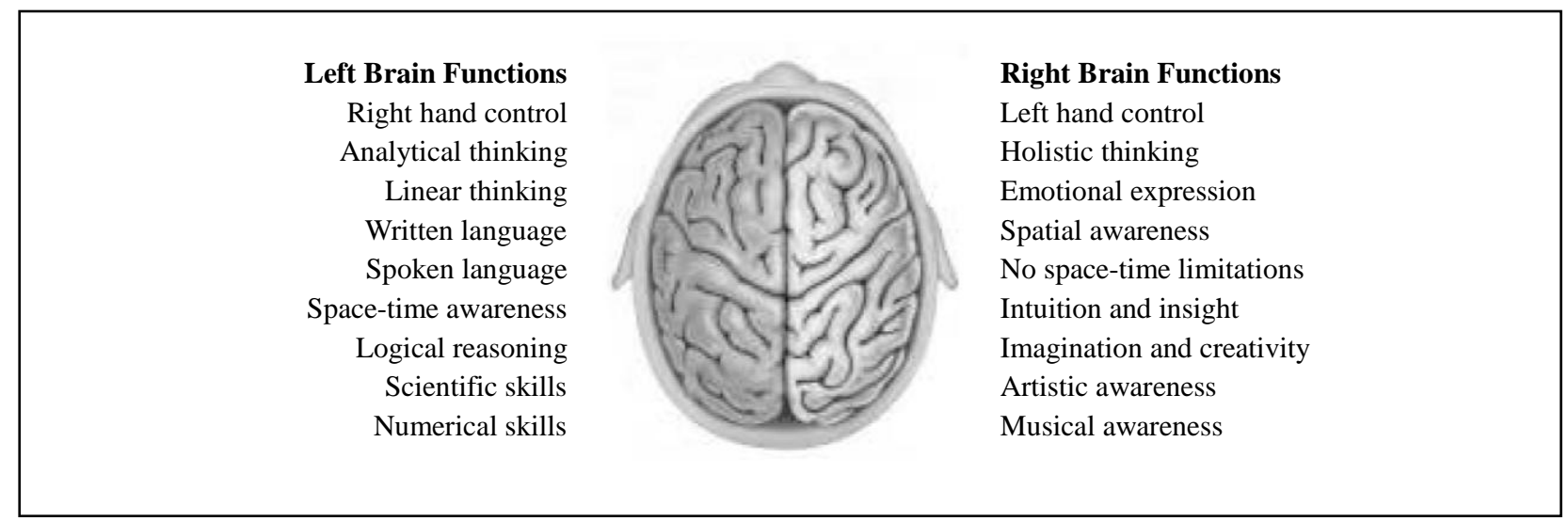

Figure 1. Functions of the left and right halves of the brain. Source: Erdmann and Stover (1991).

\section{Mental States That Facilitate Learning}

The human brain is composed of approximately 100 billion neurons that function by continuously firing energy and then resting. The frequency of their firing and resting, measured in cycles per second (cps or hertz) using an electroencephalograph (EEG), indicates different mental states, as summarized in Table 2.

Table 2

\section{Mental States Associated With Different Brainwave Frequencies}

\begin{tabular}{lll}
\hline State & Brainwave Frequency & Associated Mental State \\
\hline Gamma & higher than $40 \mathrm{cps}$ & Intense mental activity; fear \\
Beta & $14-40 \mathrm{cps}$ & Normal awake state; awareness of five senses; perception of time and space \\
Alpha & $7-14 \mathrm{cps}$ & Light sleep or deep relaxation; meditation; intuition; no time and space limitation \\
Theta & $4-7 \mathrm{cps}$ & Deep sleep; deep meditation \\
Delta & $0-4 \mathrm{cps}$ & Very deep sleep; unconsciousness \\
\hline
\end{tabular}

Note. cps means cycles per second or hertz. Source: Silva and Miele (1978).

In the normally awake Beta state, the mind is bombarded with numerous stimuli such as thoughts, needs, desires, conflicts, pressures, stresses, and etc.. Consequently, it is not free to direct more than about $10 \%$ of its attention to any one thing. At the slower Alpha state, the mind becomes more relaxed and focused, and becomes far more receptive to learning new things. This explains why children from about seven to 14 years of age, functioning mainly at the Alpha state, learn things much faster than adults who are functioning mainly at the Beta level. In the relaxed Alpha state, creativity is increased, memory is improved, and the ability to solve problems is enhanced (Silva \& Miele, 1978).

\section{Intuitive Thinking}

Recent media reports suggested that many businesses and industries were finding it increasingly difficult to stay competitive. According to Dean and Mihalasky (1974), one of the underlying reasons could be that too much reliance was being placed on short-term rational thinking. With more data generated through more sophisticated computers, there has been a tendency to slip into managing by numbers. The emphasis has been 
on the application of rationality and logic to problem-solving and decision-making, using tools such as operational research and modeling by computers that "think".

According to Dean and Mihalasky (1974), what all these have given was more incorrect, invalid, or unreliable data for making decisions, whose outcomes had been correct about as many times as when they were based on blind guessing. They attributed this to people focusing all their attention on logical and analytical thinking, without investigating the application of non-logical, intuitive thinking under rapidly changing conditions whose outcomes were hard to predict. This study found that top CEOs who performed best in intuition tests, also tended to be most successful in running their businesses.

Their observations were substantiated by the fact that many top companies hit by the 2008 global financial crisis were managed by people with high academic and professional qualifications (hard skills) backed by sophisticated management information systems. In the relatively stable years leading up to the 2008 crisis, academic and HRD programs were typically geared to the old paradigm of corporate wealth based on financial assets derived from productivity and profit, which focused on the short-term utilization of employees' skills without developing their attitudinal and behavioral competencies (Maynard \& Mehrtens, 1996). Peters (1987) also highlighted the need to develop people with new attitudes and aptitudes (soft skills).

\section{Methodology}

All such concepts and insights have to be integrated into HPD-based HRD programs that can develop employees who can sustain organizational success even under unpredictably volatile conditions.

\section{Wisdom-skills Matrix}

Having the right players determines $60 \%-80 \%$ of the success of any organization (Biehl, 1989). Developing "right players" with the necessary aptitudes, attitudes, mindsets, and behaviors requires training in hard and soft skills, closely geared to individual and organizational needs. Both individual and organizational success appears to depend on two decisive factors: wisdom - knowing what to do next, and skills— knowing how to do it (definitions by the American ichthyologist, David Starr Jordan). The wisdom-skills matrix depicted in Figure 2 broadly identifies individual competencies and training needs for achieving individual as well as organizational success.

In the wisdom-skills matrix, wisdom stems mainly from soft skills that also guide the acquisition and deployment of necessary work-related hard skills, while skills relate to such hard skills tempered with insights gained through soft skills. Without wisdom, a person or organization could strive to address wrong issues and solve irrelevant problems; without skills, a person or organization will not be able to do what needs to be done. The wisdom-skills matrix also provides a broad competency benchmark for identifying individual training needs and hiring new employees.

Individuals who are high on Wisdom but low on Skills are typically older employees who need training in relevant hard skills (e.g. computer skills); individuals who are low on wisdom but high on skills are typically technically qualified younger employees, who need more work experience and training in soft skills. People who are low on both wisdom and skills could be either novices who need extensive training in both hard and soft skills, or employees whose interests lie outside their current areas of work.

Champions with fully developed hard and soft skills are what HPD-based HRD programs must aim to produce. Focusing on champions is essential for organizational success. They are an invaluable organizational 
asset, since they are powerful change agents who can lift their colleagues to champion level through their high levels of personal motivation and engagement (Whitaker, 2012).

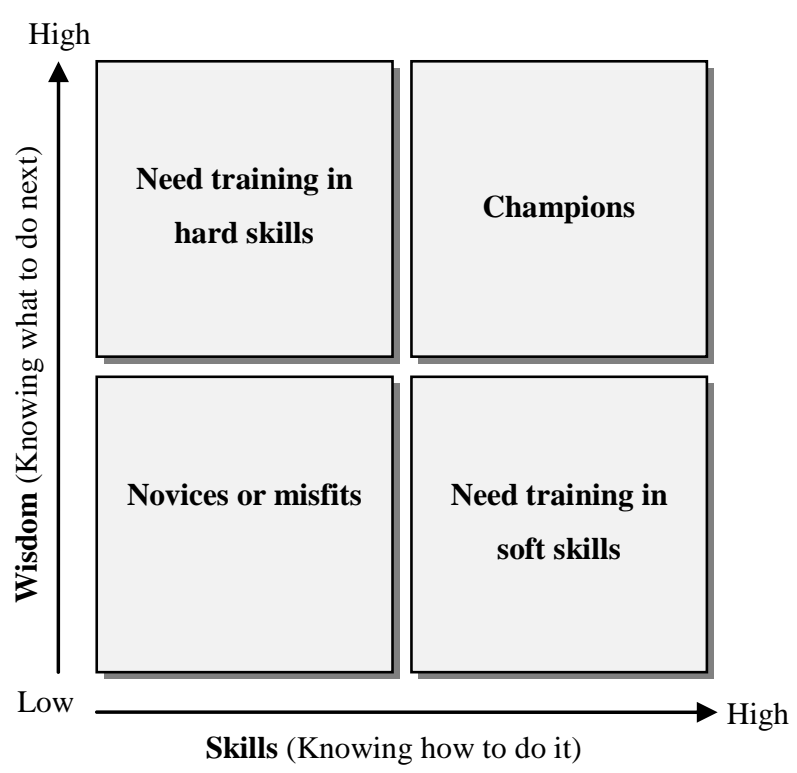

Figure 2. The wisdom-skills matrix. Source: Author's conceptualization.

A practical framework for developing both wisdom and skills is provided by the holistic five dimensional model described below.

\section{Five Dimensions of Success and Leadership}

The five dimensional model for success and leadership depicted in Figure 3 comprises of five key attributes symbolized by: heart, mind, passion, focus, and health. These five symbolic attributes appear to govern the success of individuals and organizations under most conditions. This model provides the foundation for HPD-based HRD programs for developing both hard and soft skills, and the wisdom and skills shown in Figure 2. The five dimensions of success and leadership are described below.

Heart governs the emotional intelligence (Goleman, 1995) needed for empathizing with subordinates, colleagues, superiors, customers, suppliers, and etc. through understanding and caring. It is an essential attribute for achieving personal and career success, since people are all in the "people business" dealing mostly with others (Silberman \& Hansburg, 2000). Heart also governs organizational success, since a heart-oriented culture will be able to retain staff, clients, and suppliers especially during difficult times, and business transactions depend heavily on the empathy between individuals who represent their organizations (Conant \& Norgaard, 2011).

Mind governs concrete and abstract intelligence, technology, innovation, creativity, and etc.. Since the human mind is capable of finding innovative solutions to any problem of any complexity (Silva \& Miele, 1978), it governs both individual and organizational success in today's highly complex and competitive environments. It cultivates critical thinking in employees' minds for managing risks and exploiting opportunities, alongside their daily focus on completing their tasks. The scientific community is now starting to accept that the mind, or consciousness, is a valid basis for scientific research (Nadel, 1990). More articles are beginning to appear in 
mainstream media about the relevance and importance of developing mindfulness (Pickert, 2014).

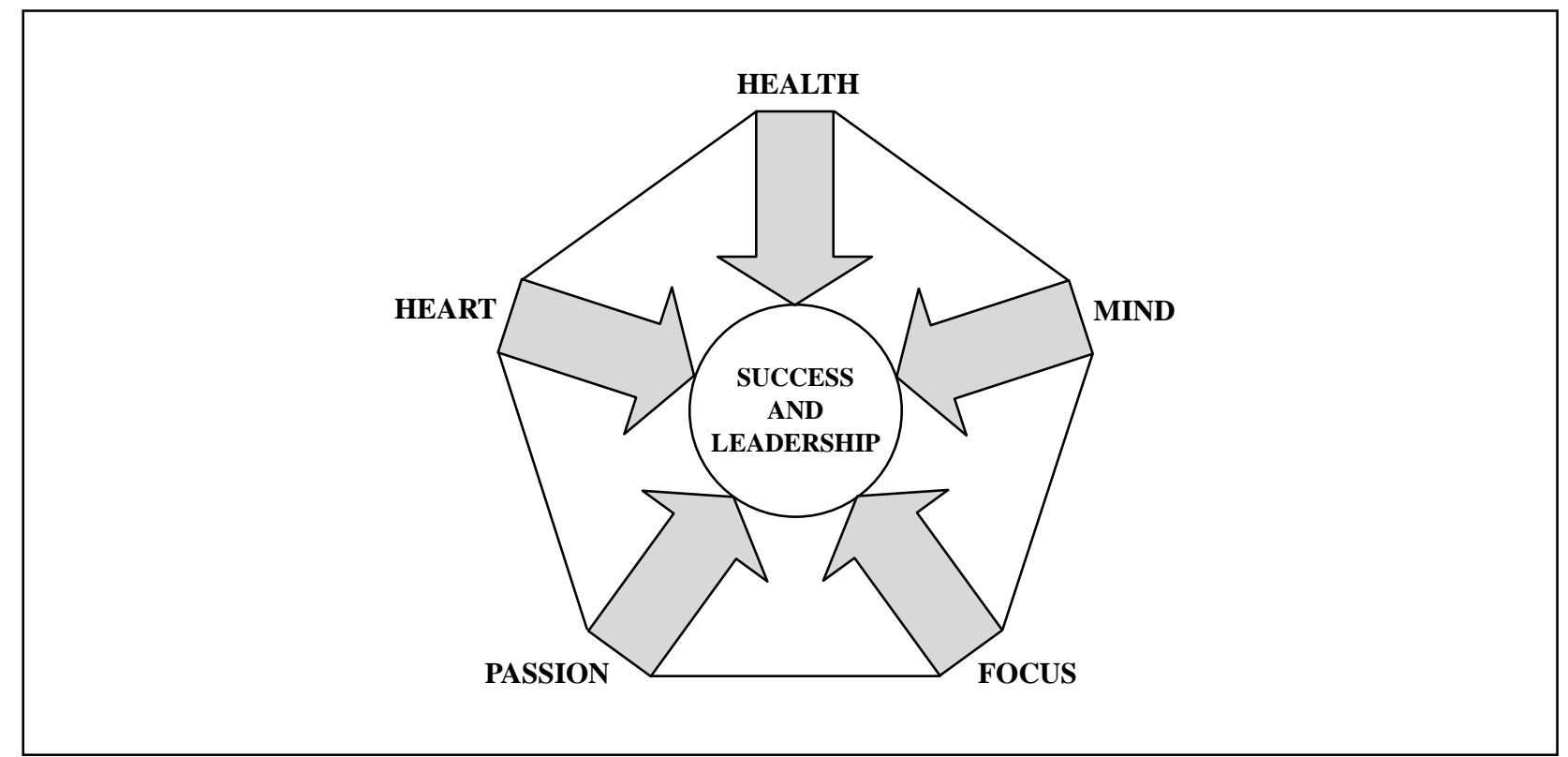

Figure 3. The five dimensions of success and leadership. Source: Author's conceptualization.

Passion is what drives people to achieve extraordinary results by aligning their hearts, minds, beliefs, and efforts. It fuels both individual and organizational success by unleashing the mental and emotional energy needed to reach ambitious goals, even against heavy odds. Passion combined with talent can produce strategies that can transform education, business, and communities in the 21st century (Robinson \& Aronica, 2009). However, passion without guidance from heart and mind can lead to rigidity, obsessions, and wasted effort.

Focus is the convergence of beliefs, resources, and effort that make individuals and organizations strive until they achieve ambitious goals, despite setbacks. Focus is also about conserving mental energy, without wasting it on mundane matters that are unimportant (Pozen, 2012). Focus is used here in preference to willpower, since focus implies desire and willingness, whereas willpower implies doing something emotionally unappealing through force of will.

Health of both individuals and organizations is the overarching foundation of the other four dimensions, since it can affect all of them positively or negatively. For organizations, health symbolizes sustainability determined by profitable growth, net asset value, liquidity, resilience, innovativeness, motivated workforce, and etc.. Organizational health is analogous to a healthy person having a strong immune system that can defend against attacks from most pathogens. Individuals can enjoy natural health by using the discovery that every sickness, disease, and ailment can be traced to a mineral deficiency (Pauling, 1986), and by following the advice of Hippocrates, the father of western medicine, who said that food should be your medicine and your medicine should be your food. This requires a change in eating habits to exclude all processed food and beverages, and include maximum Hippocrates diet staples such as raw vegetables, fresh fruits, sprouts, greens, and whole grains (Wigmore, 1983). Returning to unprocessed foods closest to their natural state will supercharge the immune system to protect against disease (Fuhrman, 2011), and eliminate inflammation of artery walls, which is the real cause of heart disease, not cholesterol (Kendrick, 2007). Stress-related and other illnesses can be easily self-healed using body-energy based, clinically proven techniques such as healing codes 
that activate healing centers in the body (Loyd \& Johnson, 2010), or emotional freedom technique (EFT) that combines Western "talk" therapy with tapping of Eastern acupressure points using fingertips (Craig, n.d.; Look, 2005).

The five attributes that comprise the five dimensions of success and leadership can best be described metaphorically using a role model for each one: heart of Mother Theresa, mind of Albert Einstein, passion of Michael Jackson, focus of Mahatma Gandhi, and the health of Fauja Singh (100-year-old marathon runner).

Developing the heart and mind dimensions will boost employees' (a) inner soft skills for self-empowerment, i.e. improved attitudinal and behavioral competencies and increased awareness, intuition, motivation, and confidence to identify significant trends and integrate new thinking into their daily work; (b) outer soft skills for interpersonal competencies, i.e. dealing with and influencing colleagues, customers, suppliers, etc. and obtaining insights through them; and (c) hard skills for maximizing organizational performance, competitiveness and sustainability, i.e. acquiring work-related knowledge, skills, tools and processes that are closely geared to changing conditions. The use of such hard and soft skills to achieve and sustain organizational success is fuelled by the dimensions of passion, focus, and health.

The heart and mind dimensions can be related to the attempts at evaluating human competencies over the past decades. In the early part of the 20th century, IQ (intelligence quotient) was considered very important; it was the only criterion used for selecting and promoting people. Later, Goleman (1995) used the research of neuroscientists and psychologists to popularize another quotient: EQ (emotional intelligence quotient). He claimed that when predicting people's success, brainpower measured by IQ tests matter less than the qualities of mind determined by emotional intelligence (Goleman, 1995). A third wave of scientific research created another quotient: SQ (spiritual intelligence quotient). Modern psychologists define spiritual intelligence as the realization of full human potential (Covey, 2004) that every human being possesses at birth. The combination of IQ, EQ, and SQ is referred to as TQ (total intelligence quotient). The heart and mind dimensions govern the development of TQ, which relates to both hard and soft skills.

\section{Developing the Five Dimensions of Success and Leadership}

In the history of human thinking, breakthrough developments took place when two different lines of thought met from different cultural or religious traditions, as observed by Werner Heisenberg, a pioneering quantum physicist (Capra, 1976). To widen the scope and effectiveness of employee training to meet future challenges, HPD-based HRD programs must also draw on lines of thought ignored by conventional approaches.

Human energy science provides a powerful methodology for improving the physical, mental, emotional, attitudinal, behavioral, and interpersonal attributes of every person, and endowing every individual with all five dimensions of success and leadership. According to Del Pe (2006), a pioneer in adapting human energy science to HRD, the human energy system is analogous to a cellular phone: The physical body is the hardware; the vitality or energy is like the battery; the emotional and mental profiles are like the software; and the antenna is the cosmic connection to the universe, through which people receive flashes of inspiration and intuitional insights.

People can learn to strengthen their cosmic connection and increase its "bandwidth" to "download" creative ideas and innovative solutions to any complex problem. This is the concept underlying SQ (spiritual intelligence quotient), which is the central and most fundamental of the intelligences (Covey, 2004), because it guides both IQ and EQ. Human energy science provides the way to boost all five dimensions of success and leadership, and all four attributes identified by Del Pe in his cellular phone analogy, by developing the energy 
centers in the human body, called Chakras.

\section{Energy Centers (Chakras) that Govern Human Abilities}

In his pioneering work in human energy science inspired by Himalayan spiritual masters, Del Pe (2006) has identified 10 main energy centers (Chakras) in the body (Figure 4), which govern all the physical, mental, emotional, and relational attributes and competencies.

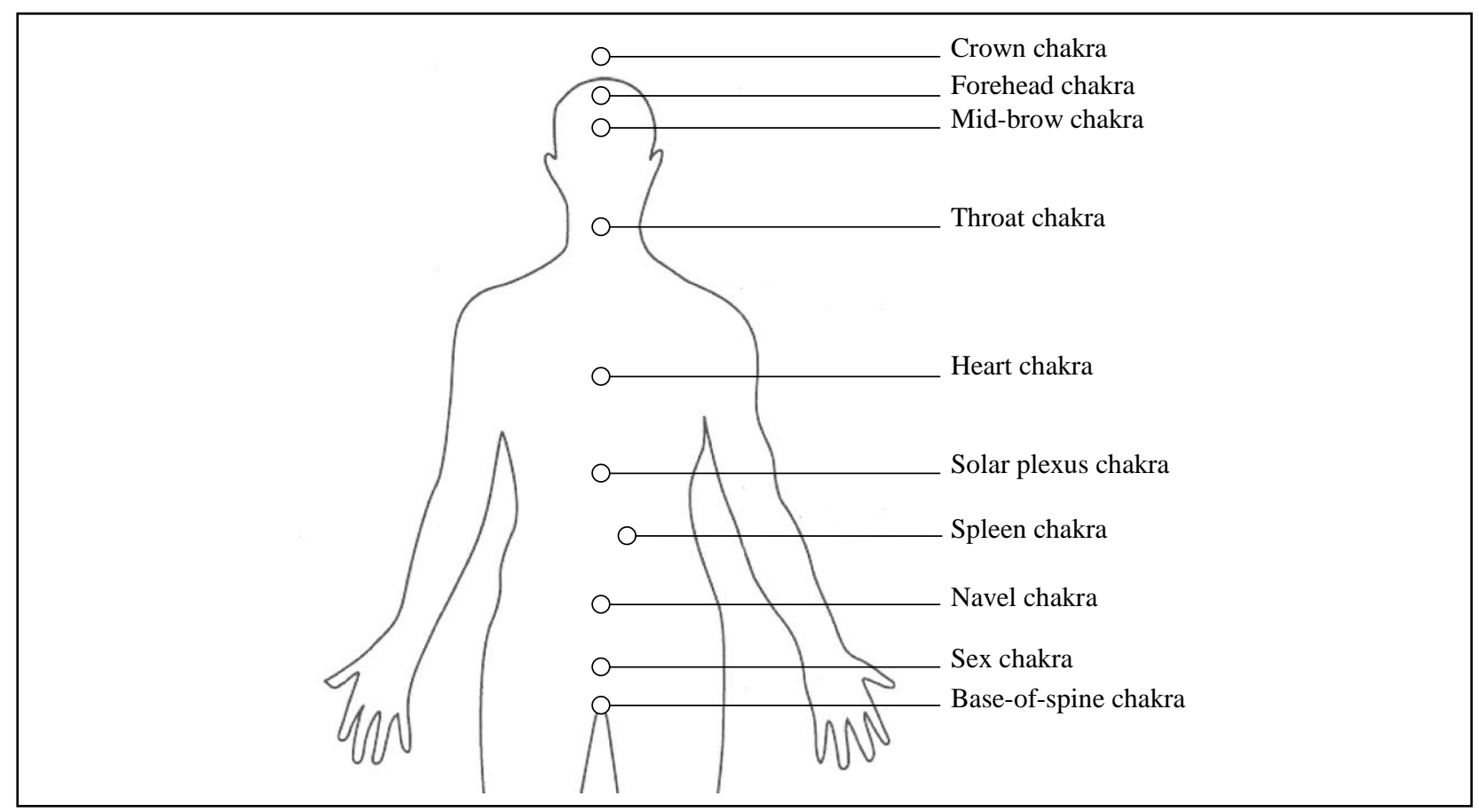

Figure 4. Ten main energy centers (Chakras) in the human body. Source: Del Pe (2006).

Each energy center depicted in Figure 4 governs the specific human attributes and competencies as summarized below (Del Pe, 2006):

- Crown: higher consciousness, spiritual intelligence, intuition, and wisdom;

- Forehead: memory, insightfulness, imaginativeness, and greater awareness;

- Mid-brow: abstract intelligence, mental willpower and stamina, focus, and constancy;

- Throat: concrete intelligence, objectivity, practicality, and producing results from plans;

- Heart: emotional intelligence, charisma, love, compassion, joy, and inner peace;

- Solar plexus: passion, desire, courage, happiness, commitment, and determination;

- Spleen: vitality, good health, and purification by elimination of toxins;

- Navel: vitality, internal power, stamina, courage, instincts, and agility;

- Sex: sexual vitality, personal magnetism, creativity, and success;

- Base-of-spine: financial and material success, physical health, and materializing goals.

\section{Developing the Energy Centers}

The level of development of these 10 energy centers governs the level of success of every individual, for example, an otherwise capable person who is unable to transform plans into results could have weak throat and base-of-spine energy centers; a manager with poor interpersonal skills would need to develop the heart center. 
In all such cases, training programs are unlikely to produce the desired results unless they rejuvenate the relevant energy centers.

Since evolution has endowed all humans with similar physical and mental attributes, developing the 10 energy centers will unleash all competencies lying mostly dormant within every person (Del Pe, 2006). Stimulating the 10 energy centers will develop all five dimensions of success and leadership (see Figure 3), and enhance both wisdom and skills (see Figure 2). This claim is indirectly corroborated by Gladwell (2008) in his 10,000-Hour Rule where he asserted that the key to achieving the highest level of success in any field is, to a large extent, a matter of practicing that specific activity for a total of about 10,000 hours.

Del Pe (2006) has formulated eight simple exercises to activate all 10 energy centers. Designed for busy people and requiring only about 10 minutes per day, these simple exercises combine gentle movements with synchronized breathing to purify, revitalize, and balance the entire human energy system. Other simple techniques that can be integrated into HPD-based HRD programs include martial arts such as Tai Chi Chuan that is based on internal energy (Chu, 1981), Chi-Kung breathing meditation developed by Taoist monks for rejuvenation, health, and longevity (Jou, 1983), and whole brain integration exercises for using both halves of the brain in tandem.

\section{Whole Brain Integration}

Most conventional HRD programs are rational left-brain oriented. In contrast, HPD-based HRD programs balance rational left-brain activities with right-brain activities and methods to enhance participants' ability to use both sides of the brain in tandem. Mind mapping is one such thinking tool based on whole brain integration (T. Buzan \& B. Buzan, 1993). A mind map pictorially develops each part of a project or concept through a tree-like drawing that expands radially outwards using words, pictures, and curved and tapered lines of different colors, because they free the mind from the rigid thinking associated with straight lines in black and white.

Activities that stimulate both halves of the brain simultaneously include juggling, dancing, creative writing, playing a musical instrument with both hands, rotating the two hands simultaneously in circles in opposite directions, using unlined paper and colored markers to take notes, and etc.. Image streaming is another brain integration exercise that combines words (left brain) with images (right brain) in real time, by creating mental images while describing them verbally in detail (Wenger \& Poe, 2004).

Since whole brain integration activities create new neural pathways and give the brain more options to think in new ways, they have to be embedded in HPD-based HRD programs geared to today's complex work environments. Such training programs must also integrate research findings on how the human brain functions and learns, and how behavior is established, for example: switching away from a primary task to do something else increases the time taken to finish that task by about 25\% (Schwartz, 2012); stating a desired behavior in negative terms (e.g. don't be late) instead of positive terms (be on time) is ineffective, because the brain tends to ignore negative operators such as "not" (Edmonds, 2012).

HPD-based training programs must start by getting the trainees into the relaxed Alpha state (see Table 2) by using simple exercises such as deep breathing or moving to music. This will quickly relax the participants mentally and physically, and facilitate the assimilation and internalization of information they will learn during the training session. Afterwards, they are likely to use such relaxation techniques to slow their brainwaves to the Alpha level to de-stress and relax whenever inspiration or innovation is needed in their daily work. In this Alpha state of relaxed concentration and non-judgmental awareness, they will be able to use the subconscious 
mind (right brain) to harness their creativity, while using the conscious mind (left brain) to maintain a rational perspective. They will also become aware of any negative emotions and limiting beliefs they may have.

\section{Transforming Negative Emotions and Limiting Beliefs}

Negative feelings such as fear, anger, resentment, envy, guilt, anxiety, and etc., arise from a person's pessimistic interpretation of past events or perceived outcomes of impending events. Negative emotions are founded primarily on fear-fear of change, failure, rejection, ridicule, and etc. (Goleman, 1995). A simple technique HPD programs can use to change negative feelings is to help participants find the "gift" in everything unpleasant in their lives. This will make them see every unpleasant thing as an opportunity for self-improvement. Shifting their point of view will make their pain and suffering vanish, and empower them by transforming negative feelings into positive ones (Xarrian, 2005).

Another critical factor that governs everyday efforts, achievements, and lives, is beliefs (positive or negative). They rule over the thoughts, feelings, attitudes, and behavior. They are the starting points of all achievements. People accomplish whatever they consistently and passionately believe in. Most of their beliefs were formed at an early age and deepened by impressionable experiences. Since people created all their beliefs, they have total power to transform them. They can replace negative beliefs with positive ones by repeatedly, energetically, and joyously imagining the desired positive outcomes in minute detail using all their senses (Palmer, 1994).

Helping people identify invisible roadblocks caused by their limiting beliefs, and replacing them with positive alternatives that support their efforts should be a major aim of HPD programs. Methods such as NLP: neuro-linguistic programming (Bandler, 2008), and EFT: emotional freedom technique or tapping (Craig, n.d.; Look, 2005), can help replace employees' emotional barriers with empowering alternatives.

\section{Analysis and Discussion}

The applications of the concepts underlying HPD-based HRD presented earlier are discussed below.

\section{Conventional HRD Model}

The conventional HRD model depicted in Figure 5 mainly focuses on improving hard skills related to products, services, processes, resources, organizational structure, and etc.. Except in a few areas such as sales training, scant attention is paid to the development of soft skills comprising of inner soft skills for self-empowerment by improving confidence, assertiveness, creativity, intuition, decision-making, and etc., and outer soft skills for becoming "people-smart" via improved interpersonal intelligence and relational competencies that are needed for dealing with and influencing others (Bolton, 1979; Silberman \& Hansburg, 2000).

\section{Inadequacy of the Conventional HRD Model}

This conventional HRD model may have been satisfactory during periods of stability when product and market profiles were clearly defined, and decisions and operations could be based mostly on rational hard skills. However, the KPMG (2012) study has shown that the HR function is now being perceived to be non-essential or ineffective, because it is not demonstrating its value to the business.

The main underlying reasons could be the absence of a synergetic link between hard and soft skills, aggravated by the underdevelopment of soft skills that enable employees to identify significant trends (either through personal awareness or feedback from others). As a result, employees are unable, unwilling, or not encouraged to detect significant trends and integrate new thinking and methods into their day-to-day work. 
Consequently, they function within their existing mental and operational frameworks, with no innovation, opportunity-seeking, or risk-evaluation underlying their daily focus on problem-solving.

The inadequacy of this conventional HRD model was illustrated during the 2008 global financial crisis, which was caused not by a natural disaster or a sudden shortage of vital resources, but by poor decision-making by individuals in positions of power in the affected companies and their regulatory agencies. Considering the high stature of many such organizations, one can presume that such people must have had well-developed educational and professional hard skills, but lacked the soft skills to sense impending dangers and initiate timely responses despite the prior warnings from astute independent agencies such as Weiss ratings.

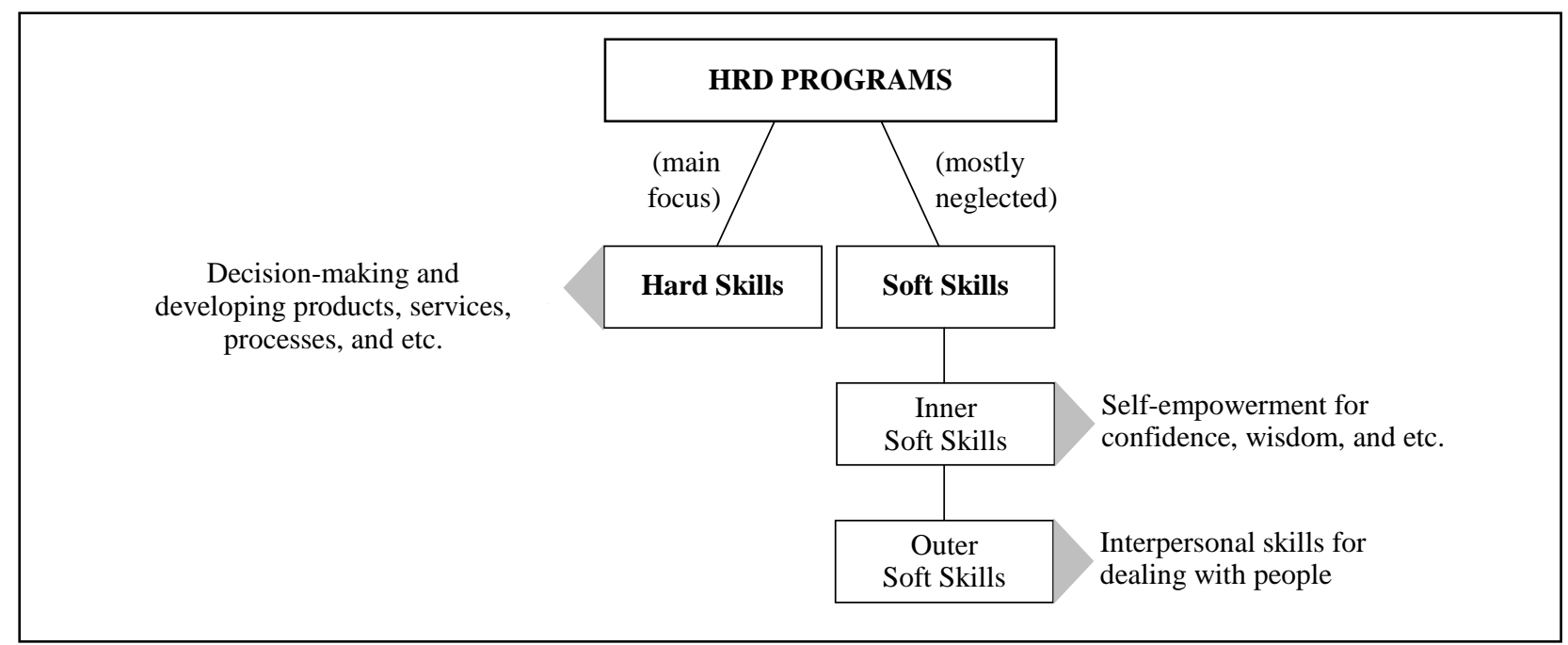

Figure 5. Conventional HRD model with unrelated hard and soft skills. Source: Author's conceptualization.

\section{Adopting a New HRD Model}

HRD programs must arm employees with the competencies they need to navigate their organizations safely through increasingly turbulent and uncertain times. This requires the parallel development of hard and soft skills, as shown in the new HRD model depicted in Figure 6. Inner soft skills for self-empowerment must be developed first, since they form the empowering foundation for developing outer soft skills for improving interpersonal competencies.

In this new HRD model, intuitive insights sensed by empowered employees at all levels from changes in the operating environment, combined with relational insights gathered from others through interpersonal competencies, will guide the acquisition, modification, and deployment of hard skills. This provides a powerful and on-going employee-based feedback mechanism for quickly adapting to rapidly changing conditions in operating environments.

Under this new model, frontline employees who are closest to changes in ground-level conditions (boundary spanners) would use their analytical hard skills and intuitive soft skills to sense significant trends and send back intelligence up the corporate ladder. Staff at higher levels would also have enhanced hard and soft skills to interpret such trends and respond to the underlying opportunities or threats, which could affect products, services, operating procedures, organizational structures, or even business models. Such an adaptive operational structure, driven by the workforce and guided by top management, would have the flexibility to maximize organizational performance, especially under unpredictably turbulent conditions. 


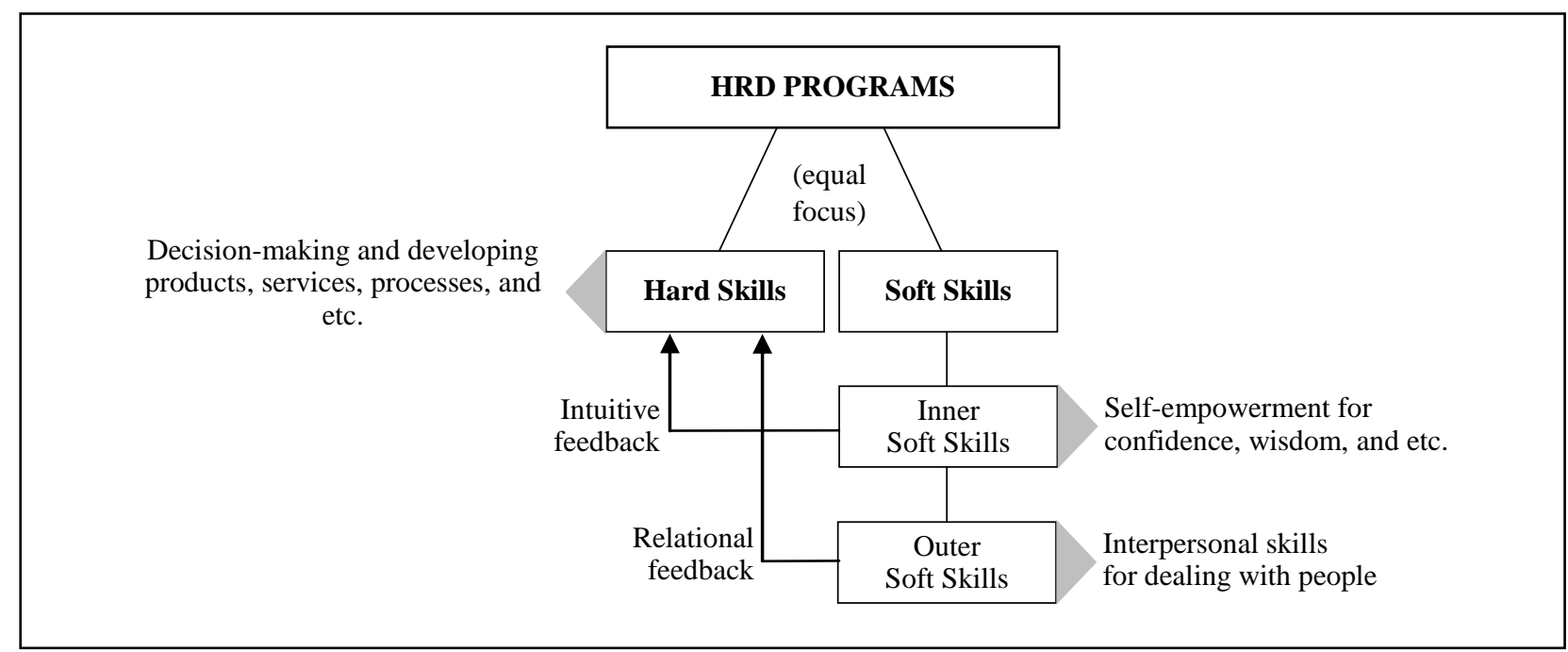

Figure 6. A new model for HRD with feedback from soft skills to hard skills. Source: Author's conceptualization.

This new HRD model requires moving away from rigid and predefined work-related employee training, towards holistic HPD-based programs that can unleash the huge potential lying mostly dormant within every employee through the parallel development of concrete hard skills and abstract soft skills. This will produce "learning organizations" in which empowered employees will be self-motivated to acquire new knowledge and skills geared to changing conditions in operating environments (Pedler, Burgoyne, \& Boydell, 1991), for accurately interpreting changing conditions and implementing viable responses without conventional delays.

\section{A Pilot Project to Validate the New HRD Model}

With the 5-star hotel industry in Colombo becoming fiercely competitive with many new global entrants, the Taj Samudra luxury hotel needed novel strategies for sustaining its growth after reopening after refurbishment on 1st November, 2013. It decided to enhance its guest experience by energizing, empowering, and engaging its entire workforce. The goal was to give each employee the energy, confidence, and commitment to deliver an unsurpassed brand experience to every guest, founded on legendary Sri Lankan hospitality.

Over 600 Taj employees at semiskilled, skilled, supervisory, and managerial levels jointly underwent the same HPD-based training, aimed at collectively unleashing their dormant physical and mental power by developing all components of the five dimensional model. It empowered all employees at all levels and gave them the freedom to deliver a superlative guest experience in an autonomous and creative way, within specified operational guidelines. As a result, the overall service experience component in their guest satisfaction tracking index shot up by $40.4 \%$ within five months after reopening, as shown in Table 3 .

Table 3

Overall Service Experience Ratings After 1 November 2013

\begin{tabular}{|c|c|c|c|c|c|c|}
\hline & $\begin{array}{l}\text { Nov. } \\
1-30\end{array}$ & $\begin{array}{l}\text { Dec. } \\
1-31\end{array}$ & $\begin{array}{l}\text { Jan. } \\
1-31\end{array}$ & $\begin{array}{l}\text { Feb. } \\
1-28\end{array}$ & $\begin{array}{l}\text { Mar. } \\
1-31\end{array}$ & $\begin{array}{l}\text { Change in } 5 \\
\text { months }\end{array}$ \\
\hline Overall service experience & 52 & 57 & 65 & 61 & 73 & $+40.4 \%$ \\
\hline
\end{tabular}

Source: Taj Samudra Hotel, Colombo.

Training methodology used in the pilot project. The HPD-based workshop developed inner soft skills 
for self-empowerment, and outer soft skills for interpersonal competency improvement. It guided participants through an energizing and empowering process that helped them to unleash the vast physical and mental power lying mostly dormant within them, eliminate negative emotions such as fear, and transform limiting beliefs that weaken their self-confidence.

The program used simple but powerful techniques drawn from widely different cultures and traditions, such as neuro-linguistic programming (Bandler, 2008), Japanese martial art Aikido (Westbrook \& Ratti, 1970), Chinese Tao meditation (Jou, 1985), and Himalayan energy practices (Del Pe, 2006). To integrate all the newly learned practices into participants' daily lives at home and work, they agreed to invest about 20 minutes every day to follow a simple daily routine for at least three weeks (Maltz, 1960).

\section{Conclusions}

No coverage was found in background literature on the relevance or application of human energy concepts to HRD. The results of the pilot project at the Colombo Taj Samudra Hotel suggest that a HPD-based HRD model can produce significant improvements in customer service that drives organizational performance. The HPD-based new model addresses wide-ranging HR-related issues that were identified, such as: (a) competencies that served HR well in the past will not be enough to propel it into the future; (b) only $17 \%$ out of 418 senior executives in a global survey agreeing that HR is demonstrating its value to the business; (c) the statement "knowledge + behavior = success" demanding the equal development of hard and soft skills; (d) organizational dependence on employees at all levels to sustain success under turbulent conditions.

Instead of developing work-related hard skills, this new HPD-based HRD model develops all five dimensions of success and leadership using new methods gleaned from human energy science, NLP, internal martial arts, and etc.. It empowers all employees and arms them with both wisdom and skills, comprising of the rational hard skills and behavioral soft skills they need to drive organizational success by optimizing the thousands of decisions made every day in every department at every level.

The conceptual and operational framework for this holistic HPD-based HRD model transforms the theoretical concept of "learning organizations" into an everyday operational reality, by empowering employees at all levels. By deploying employee-based feedback obtained through individual empowerment and engagement, this new model enables organizations to exploit opportunities and mitigate risks quickly, especially under turbulent conditions that are hard to predict. It unleashes and channels the vast inborn human potential lying mostly dormant within every employee at every level into an everyday business innovation ideology that can sustain success even under unfavorable operating conditions.

\section{Policy Recommendations}

HPD-based HR policies that can enhance organizational performance include the following:

(1) Validate the key concepts and methodologies presented in this conceptual paper, such as the wisdom-skills matrix and the five dimensional model of success and leadership, through qualitative research using tools such as case studies, in-depth interviews, and open-ended questionnaires;

(2) In addition to developing work-related hard skills, HRD programs must also develop inner soft skills for self-empowerment and outer soft skills for interpersonal competencies;

(3) Use HPD programs to achieve company-wide acquisition of wisdom and skills, by developing all five dimensions of leadership in every employee at every level; 
(4) Create an entrepreneurial culture to improve organizational performance by motivating the energized, empowered, and engaged employees produced by HPD-based HRD programs.

\section{References}

Bandler, R. (2008). Get the life you want: The secrets to quick and lasting life change with neuro-linguistic programming.

Deerfield Beach: Health Communications Inc..

Biehl, B. (1989). Increasing your leadership confidence: Fine-tune your leadership skills. Sisters: Questar Publishers.

Bolton, R. (1979). People skills: How to assert yourself, listen to others, and resolve conflicts. Upper Saddle River: Prentice-Hall.

Buzan, T., \& Buzan, B. (1993). The mind map book: How to use radiant thinking to maximise your brain's untapped potential.

London: BBC Books.

Capra, F. (1976). The Tao of physics. Glasgow: William Collins Sons.

Chu, C. K. (1981). T'ai chi ch'uan: Principles and practice. New York: Sunflower Press.

Conant, D. R., \& Norgaard, M. (2011). Touch points: Creating powerful leadership connections in the smallest of moments. San Francisco: Jossey-Bass.

Covey, S. R. (2004). The 8th habit: From effectiveness to greatness. New York: Free Press.

Craig, G. (n.d.). The most inspirational EFT video with founder Gary Craig. Retrieved from http://www.youtube.com/watch?v=ZKDhRohzSdU

Dean, D., \& Mihalasky, J. (1974). Executive ESP. Upper Saddle River: Prentice-Hall.

Del Pe. (2006). From success to fulfillment: Applying the wisdom of the Himalayan masters. Nishat Colony: Anthem.

Edmonds, S. C. (2012). Build your desired culture with "do" messages. Retrieved from http://www.smartblogs.com/leadership/2012/09/11/secure-desired-culture-do-not-dont-messages/

Erdmann, E., \& Stover, D. (1991). Beyond a world divided: Human values in the brain-mind science of Roger Sperry. Lincoln: Authors Choice Press.

Fuhrman, J. (2011). Super immunity: The essential nutrition guide for boosting your body's defenses to live longer, stronger and disease free. New York: Harper Collins Publishers.

Gladwell, M. (2008). Outliers: The story of success. New York: Little, Brown and Company.

Goleman, D. (1995). Emotional intelligence: Why it can matter more than IQ. New York: Bantam Books.

Gupta, P. (2011). The innovation solution: Making innovation more pervasive, predictable and profitable. Schaumburg: Create Space Independent Publishing Platform.

International Monetary Fund. (2014). World economic outlook April 2014: Recovery strengthens, remains uneven. Retrieved from http://www.imf.org/external/Pubs/ft/weo/2014/01/pdf/text.pdf

Jou, T. H. (1983). The Tao of meditation: Way to enlightenment. New York: Tai Chi Foundation.

Jou, T. H. (1985). The Tao of Tai-Chi Chuan: Way to rejuvenation. New York: Tai Chi Foundation.

Kaye, B., \& Giulioni, J. W. (2012). Help them grow or watch them go: Career conversations employees want. San Francisco: Berrett-Koehler Publishers.

Kendrick, M. (2007). The great cholesterol con: The truth about what really causes heart disease and how to avoid it. London: John Blake Publishing.

Klaus, P. (2007). The hard truth about soft skills: Workplace lessons smart people wish they'd learned sooner. New York: Harper Collins Publishers.

KPMG. (2012). Rethinking human resources in a changing world. Retrieved from http://www.kpmg.com/Global/en/IssuesAndInsights/ArticlesPublications/hr-transformations-survey/Documents/hr-transform ations-survey-full-report.pdf

Look, C. (2005). Attracting abundance with EFT_Emotional freedom technique. Bloomington: Author House.

Loyd, A., \& Johnson, B. (2010). The healing code. Peoria: Intermedia Publishing Group.

Maltz, M. (1960). Psycho-cybernetics. New York: Pocket Books.

Maynard, H. B., \& Mehrtens, S. E. (1996). The fourth wave: Business in the 21st century. San Francisco: Berrett-Koehler Publishers.

McCann, J. M. (n.d.). Beyond survival: Devising strategies in an uncertain world. Retrieved from https://4good.org/morrie-warshawski-consultant/beyond-survival-devising-strategies-in-an-uncertain-world-by-john-m-mcca nn 
McIlvaine, A. R. (2012). Brave new HR. Retrieved from http://www.hreonline.com/HRE/view/story.jhtml?id=533347125

Milne, P. (2012). The people skills revolution: A step by step approach to developing sophisticated people skills. Cranbrook: Global Professional Publishing.

Nadel, L. (1990). Sixth sense: Unlocking your ultimate mind power. Lincoln: iUniverse.

Österberg, R. (2003). Corporate renaissance: Business as an adventure in human development. New York: Paraview.

Oxford Economics. (2012). Global talent 2021: How the new geography of talent will transform human resource strategies.

Retrieved from https://www.oxfordeconomics.com/Media/Default/Thought\%20Leadership/global-talent-2021.pdf

Palmer, H. (1994). Living deliberately. Altamonte Springs: Star's Edge International.

Pauling, L. (1986). How to live longer and feel better. New York: W. H. Freeman.

Pedler, M., Burgoyne, J., \& Boydell, T. (1991). The learning company: A strategy for sustainable development. Maidenhead: McGraw-Hill Publishing Company.

Peters, T. (1987). Thriving on Chaos: Handbook for a management revolution. New York: Alfred A. Knopf.

Pickert, K. (2014). The mindful revolution. Time, 183(4), 34-38.

Pozen, R. C. (2012). Extreme productivity: Boost your results, reduce your hours. New York: Harper Collins Publishers.

Robinson, K., \& Aronica, L. (2009). The element: How changing your passion changes everything. New York: Penguin Group.

Schwartz, T. (2012). The magic of doing one thing at a time. Retrieved from https://hbr.org/2012/03/the-magic-of-doing-one-thing-a.html\#disqus_thread

Silberman, M. L., \& Hansburg, F. (2000). People smart: Developing your interpersonal intelligence. San Francisco: Berrett-Koehler Publishers.

Silva, J., \& Miele, P. (1978). The Silva mind control method. New York: Pocket Books.

Society for Human Resource Management. (2012). SHRM elements for HR success: Competency model. Retrieved fromhttp://www.shrm.org/hrcompetencies/documents/competency\%20model\%208\%200.pdf

Towers Watson. (2012). Engagement at risk: Driving strong performance in a volatile global environment. Retrieved from http://towerswatson.com/assets/pdf/2012-Towers-Watson-Global-Workforce-Study.pdf

Ulrich, D., Younger, J., Brockbank, W., \& Ulrich, M. (2011). Competencies for HR professionals working outside-in. Retrieved from

http://rbl-net.s3.amazonaws.com/hrcs/2012/Competencies\%20for\%20HR\%20Professionals\%20Working\%20Outside-In.pdf

Wenger, W., \& Poe, R. (2004). The Einstein factor. New York: Random House.

Wentz, F. H. (2012). Soft skills training: A workbook to develop skills for employment. Schaumburg: Accelper Consulting/Create Space.

Westbrook, A., \& Ratti, O. (1970). Aikido and the dynamic sphere: An illustrated introduction. North Clarendon: Tuttle Publishing.

Whitaker, T. (2012). Shifting the monkey: The art of protecting good people from liars, criers, and other slackers. Indiana: Triple Nickel Press.

Wigmore, A. (1983). The Hippocrates diet and health program. Pennington: Avery Publishing.

Xarrian, S. (2005). Outrageous mastery. Retrieved from http://www.masteryourbeliefs.com/gifts/life-of-mastery/ 